\title{
Future Change of Occurrence Frequency of Baiu Heavy Rainfall and Its Linked Atmospheric Patterns by Multiscale Analysis
}

\author{
Yukari Osakada $^{1}$ and Eiichi Nakakita ${ }^{2}$ \\ ${ }^{1}$ Graduate School of Engineering, Kyoto University, Kyoto, Japan \\ ${ }^{2}$ Disaster Prevention Research Institute, Kyoto University, Kyoto, Japan
}

\begin{abstract}
The future change of heavy rainfall (meso- $\beta$ scale) in the Baiu season, the atmospheric patterns (over meso- $\alpha$ scale) of sea level pressure and surface vapor flux, and the connection between them were investigated by analyzing multiple datasets of a highresolution non-hydrostatic regional climate model (NHRCM05) for better simulating heavy rainfall, a coarser-resolution global atmospheric climate model (AGCM20) embedding the NHRCM 05, and a huge database for Policy Decision-Making for Future climate change (d4PDF) with a coarser-resolution. As a result, northern Japan and Japan-sea-side areas have a statistically significant increase of heavy rainfall that is caused by an increase in the atmospheric patterns with westward-protruding Pacific high and northward-invading vapor flux along the periphery of the high. In the Pacific side in eastern Japan, the typical atmospheric pattern prone to heavy rainfall will change in the future as it will decrease the occurrence frequency of the atmospheric pattern that presently caused heavy rainfall with cyclones located at south of Japan. Besides, the atmospheric pattern with westward-protruding pacific high, that presently caused heavy rainfall mainly in western Japan, will expand the area of heavy rainfall eastward in the future due to an eastward-invading vapor flux.
\end{abstract}

(Citation: Osakada, Y., and E. Nakakita, 2018: Future change of occurrence frequency of Baiu heavy rainfall and its linked atmospheric patterns by multiscale analysis. SOLA, 14, 79-85, doi:10.2151/sola.2018-014.)

\section{Introduction}

Heavy rainfall in the Baiu season (mainly from June to July in Japan) is one of the main factors causing severe water-related disasters in Japan. As the warming trend becomes more significant, it is an urgent issue to project detailed future changes of Baiu heavy rainfall under climate change. The typical Baiu heavy rainfall is a phenomenon of back-building type (Seko 2010) in the small meso- $\beta$ scale under atmospheric circumstances of Baiu front in a scale relatively larger than the meso- $\alpha$ scale. Thus, it is necessary to capture Baiu heavy rainfall from multiple spatial scales.

In the KAKUSHIN Program (Kitoh et al. 2009), Kanada et al. (2012) discovered an increase of extreme precipitation in early July in the future climate by analyzing a 5-km-mesh non-hydrostatic regional climate model (NHRCM05) under the A1B scenario proposed in IPCC Special Report on Emission Scenarios (SRES; IPCC 2000). Nested in an outer 20-km-mesh global atmospheric climate model (AGCM20), NHRCM05 outputs 30-minutes precipitation. This high spaciotemporal resolution enables us to obtain Baiu heavy rainfall as precipitation output like a weather radar image. Therefore, Nakakita et al. (2012) manually picked up Baiu heavy rainfall events from the precipitation output of NHRCM05 under the SRES A1B scenario with only single ensemble member (Hereinafter, the Baiu heavy rainfall events represented by precipitation distributions are called BHRs, and general Baiu heavy rainfall is called heavy rainfall). They also revealed increasing trends of BHRs in early July as well as

Corresponding author: Yukari Osakada, Kyoto University, Gokasyo, Uji, Kyoto 611-0011, Japan. E-mail: osakada@hmd.dpri.kyoto-u.ac.jp. around Northern Japan. Additionally, Nakakita et al. (2016, 2017) extracted atmospheric patterns of sea level pressure and surface vapor flux prone to heavy rainfall referring to the BHRs' datasets (Nakakita et al. 2012), and retrieved the patterns' occurrence frequency using a huge ensemble database in a coarser-resolution. However, the linkage between the future change of heavy rainfall and corresponding atmosphere has not been clarified in those literatures yet.

In the SOUSEI Program succeeding to the KAKUSHIN Program, a new dataset of NHRCM05 was developed by nested in AGCM20 (Mizuta et al. 2012) under the scenario of Representative Concentration Pathways 8.5 (RCP8.5; IPCC 2013). These models have four SST ensembles, called $\mathrm{c} 0 \sim \mathrm{c} 3$ (Mizuta et al. 2014). c1 c3 are made by a cluster analysis of SST change patterns projected in Coupled Model Intercomparison Project phase 5 (CMIP5). $\mathrm{c} 0$ is the total mean. The patterns of $\mathrm{c} 0$ and c2 are associated with El-Nino, however c1 has a characteristic opposite to c2. c3 has significant warming in the western North Pacific. However, the ensemble number is still insufficient for statistical analysis. Hence, Mizuta et al. (2016) performed a huge ensemble experiments, of which the dataset is called Database for Policy Decision-Making for Future climate change (d4PDF). In these future experiments, the SST forcing is from CMIP5 same as AGCM20/RCM05 and the amplitude of warming is kept stationary $4 \mathrm{~K}$ warmer than the preindustrial climate, which is corresponding to that around the end of the twenty-first century under RCP8.5, throughout the 60-year integration. d4PDF has outputs in two resolutions, including a $60-\mathrm{km}-\mathrm{mesh}$ global atmospheric model (d4PDF60) and the nested 20-km-mesh regional climate model (d4PDF20). Particularly, d4PDF60 has 100 and 90-ensembles of climate experiments in the present (1951-2010) and future (2051-2110), respectively. d4PDF20 has 50 and 90-ensembles for the present and future climates. d4PDF enables us to estimate probabilistic future changes in extreme events. However, d4PDF20 is not finer enough to represent BHRs while NHRCM05 can.

This study aims to estimate the detailed future change of heavy rainfall by clarifying its linkage with corresponding atmospheric patterns. To accurate reveal multiscale effects, we used NHRCM05's precipitation output for BHRs, and utilized AGCM20 and d4PDF20 for atmospheric patterns of sea level pressure, $P_{\text {slp }}$, and surface vapor flux, $F_{\mathrm{s}}$. To reinforce the linkage, we also analyzed some real BHRs in the past. In this study we shall focus on the regional future change as a preliminary analysis for the detailed future change of heavy rainfall by multiscale analysis.

\section{Data and methodology}

The datasets we used are NHRCM05 and AGCM20 under RCP8.5 as well as d4PDF20. From NHRCM05 we extracted the precipitation output from June $1^{\text {st }}$ to August $31^{\text {st }}$ for the period of 20-years in present (1981-2000) and four SST ensembles c0 c3 of future (2077-2096). Because some heavy rainfall of back-building type often occurred even in August, the period of August is included in our analysis. As is the outer model covering NHRCM05, AGCM20 with hourly outputs was used to check the atmospheric patterns of $P_{\text {spp }}$ and $F_{\mathrm{s}}$, corresponding to the BHRs found in the nested NHRCM05 (Hereinafter, the BHRs atmo- 


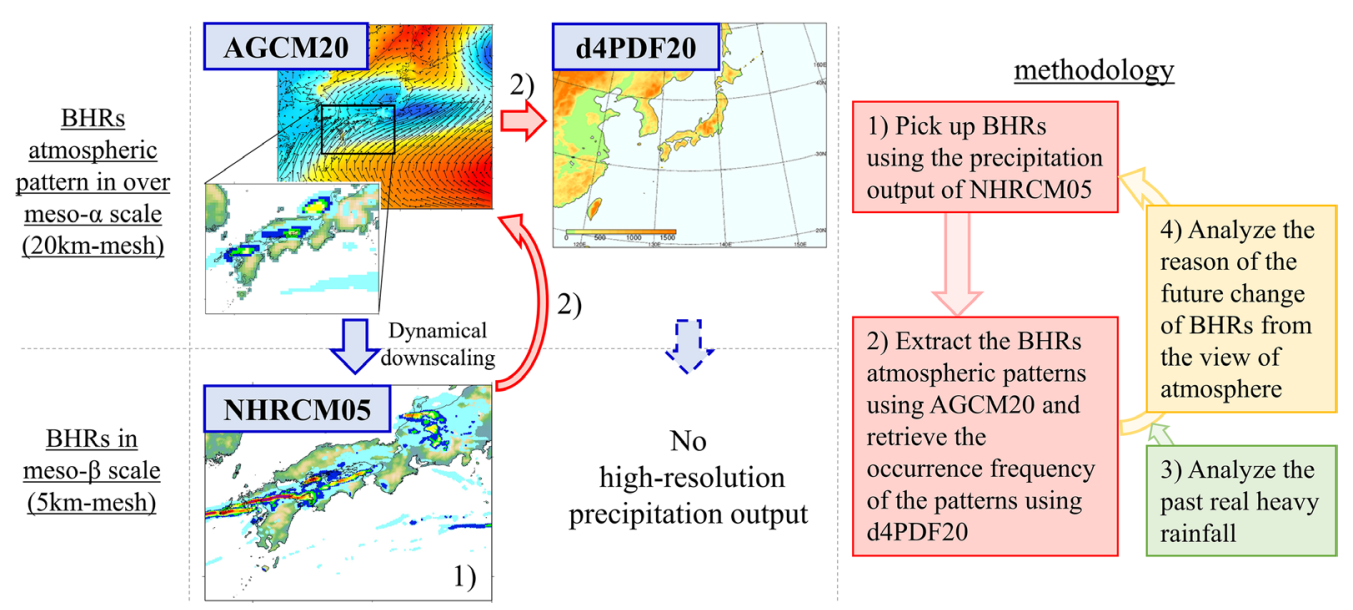

Fig. 1. The framework and methodology of this study.

spheric patterns is abbreviated as BHRAP). Then, d4PDF20 with hourly output was utilized for retrieving the occurrence frequency of these BHRAP. For analyzing the past real BHRs, we used weather radar data for rainfall event's spatial distributions and locations, and used Japanese 55-year Reanalysis (Kobayashi et al. 2015), JRA55, for spatial distributions of $P_{\text {slp }}$ and $F_{\mathrm{s}}$.

For analyzing BHRAP for $P_{\text {slp }}$ and $F_{\mathrm{s}}$, we used the method of Self-organizing map (SOM), which is a non-linear classification technique for principal component analysis. As is a pattern recognition technique, SOM can project high-dimensional variables, that is atmospheric variables of $P_{\mathrm{slp}}$ and $F_{\mathrm{s}}$, to a visually understandable low-dimensional array. Each element in SOM is denoted as a node. Nodes distributed relatively nearby in a map possess a similar feature. Taking the advantage of SOM, we can easily achieve data classification of the same dimensional atmospheric data into one node having a minimum Euclid distance with that data. For more details, one can refer to other studies (Camus et al. 2011; Ohba et al. 2014, 2016).

Figure 1 illustrates the framework of this research. The methodology is briefly explained as follows.

1) Referring to the criteria listed in Supplement 1 (Nakakita et al. 2012), we manually picked up BHRs from the spaciotemporal precipitation distributions of NHRCM05 under RCP8.5 and estimated the statistics of the future change of BHRs. Here, even if a tropical cyclone affects Baiu front remotely, we extract all BHRs which are not directly caused by a tropical cyclone and belong to the type of meso- $\beta$ back-building.

2) From AGCM 20 we extracted the BHRAPs corresponding to BHRs obtained from NHRCM05. The analysis area for atmosphere spans from $120^{\circ} \mathrm{E}$ to $155^{\circ} \mathrm{E}$ and from $20^{\circ} \mathrm{N}$ to $50^{\circ} \mathrm{N}$. Also, we retrieved the future change of the occurrence frequency of these BHRAPs from d4PDF20. Then, the method of SOM was applied to classify the atmospheric variables and to estimate the future change of these atmospheric variables.

3) The features of real BHRs in the past and corresponding BHRAP were investigated by using weather radar data and JRA55.

4) Based on the results of 1) 3), we revealed the linkage between heavy rainfall and atmosphere, and analyzed the cause of the BHRs' future change in terms of the statistical information of the atmosphere's future change obtained from d4PDF20.

\section{Results}

\subsection{The future change of Baiu heavy rainfall events}

Figure 2 shows the future change of the BHRs' appearance frequency for 20 years by summarizing all events obtained from NHRCM05. The areas in red (pink) has a 5\% (10\%) statistically significant increase in BHRs. The BHRs' appearance frequency is shown in the lower bar charts in which the asterisk symbol ** (*) mean $5 \%(10 \%)$ statistically significant increase. The frequency of BHRs will increase almost everywhere in Japan. Especially in Hokkaido, Tohoku and Hokuriku, where seldom experienced BHRs in the present climate of NHRCM05, we discovered a statistically significant increase in BHRs. This indicates that these areas will face a new risk of heavy rainfall-triggered-disasters in the future. As for Kyusyu, the increase numbers of BHRs for $\mathrm{c} 0 \sim \mathrm{c} 3$ are considerable large, though the differences are not statistically significant except for $\mathrm{c} 1$. The pacific side area, e.g., Kanto or Tokai, also has no statistically significant differences.

\subsection{The future change of atmospheric patterns}

For BHRAPs we extracted the spatial distributions of 10-daysaveraged $P_{\text {slp }}$ and $F_{\mathrm{s}}$ from AGCM20 corresponding to the BHRs obtained from NHRCM05 using SOM method. For obtaining proper atmospheric classifications, Nakakita et al. (2017, 2018) treated independently each variable on each one-dimensional SOM rather than treated all variables on one two-dimensional SOM conventionally. Then, they constructed a two-dimensional SOM by assigning the two one-dimensional SOMs as vertical and horizontal axes, respectively. Each one-dimensional SOM is composed of 50 nodes. In this study, we cited and expanded these results. The datasets for the SOM construction were AGCM20's present and future $\mathrm{c} 0$ simulations. By analyzing all future ensembles of $\mathrm{c} 0 \sim \mathrm{c} 3$ in AGCM20, we discovered that the results of $\mathrm{c} 1 \sim \mathrm{c} 3$ are almost equivalent to the one of $\mathrm{c} 0$. Thus, the $\mathrm{c} 0$ result is taken as a representative in the following analysis.

Figure 3 a shows the classification of 10-days-averaged $P_{\text {slp }}$ and $F_{\mathrm{s}}$ from AGCM20 on SOMs. White circles denote the 10-daysaveraged atmosphere without BHR in NHRCM05 within 10-days, and red (blue) circles or stars denote the atmosphere with at least one or greater than three BHRs in future (present) climate. Figure $3 \mathrm{~b}$ shows the classification of 10-days-averaged $P_{\text {slp }}$ and $F_{\mathrm{s}}$ from d4PDF20 in terms of the same pattern at each node in Fig. 3a, and the color represents the number difference between the future and present climates classified into each node. We identified eight clusters of $1 \sim 4$ and $A \sim D$ using the U-matrix method (Ultsch 1990), which we calculate Euclid distances between two adjacent nodes and splits the particular two nodes with relatively large Euclid distances, and the cluster-averaging $P_{\text {slp }}$ and $F_{\mathrm{s}}$ are shown in Fig. 3c. The nodes inside the circled clusters in Fig. $3 \mathrm{~b}$ have $1 \%$ statistical significant differences of the numbers between the future and present climate. d4PDF are calculated under the similar conditions of future scenario and SST in AGCM20, therefore we classified d4PDF20 into SOM made from AGCM20 to clearly show the atmospheric future change with its huge ensembles.

We can find that patterns 1 4 are highly associated with the BHRs from Fig. 3a, thus they are regarded as the BHRAPs. These patterns have the characteristics of westward-protruding Pacific 


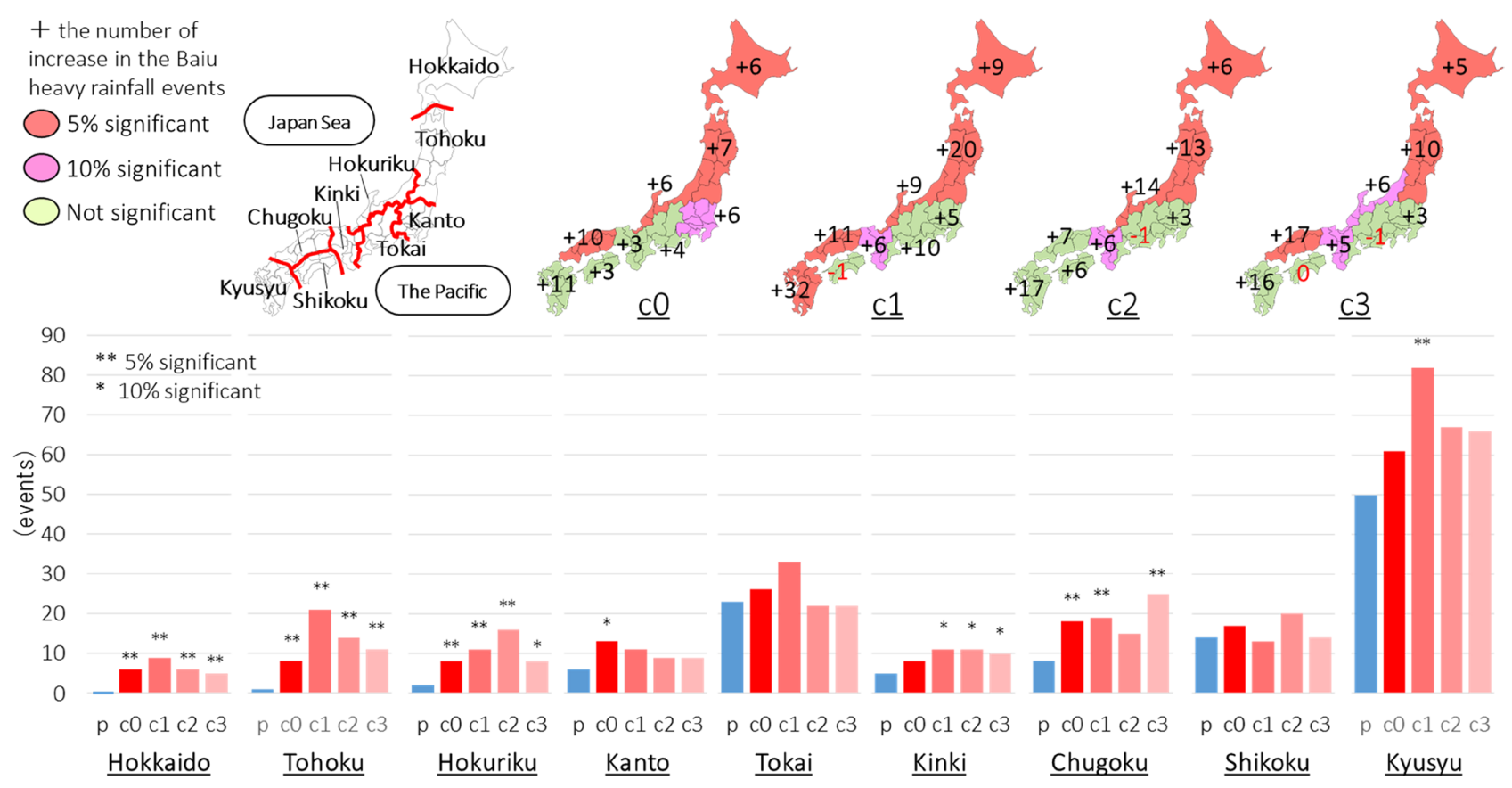

Fig. 2. The future change of BHRs' appearance frequency for 20 years projected by NHRCM05. Figures in upper line show the future change which the areas in red and pink have $5 \%$ and $10 \%$ statistically significant increase. Figures in lower line show the appearance frequency for the present and future climates. The asterisk symbols ** and * respectively denote the $5 \%$ and $10 \%$ statistically significant increase. c0, c1, c2 and c3 denote individual ensemble members of future experiments with different SST change patterns. The SST patterns in c0 and c2 are similar to the observed interannual variation pattern of ENSO and the pattern of $\mathrm{c} 1$ is an opposite characteristic to $\mathrm{c} 2$. And $\mathrm{c} 3$ has larger warming in the western North Pacific.

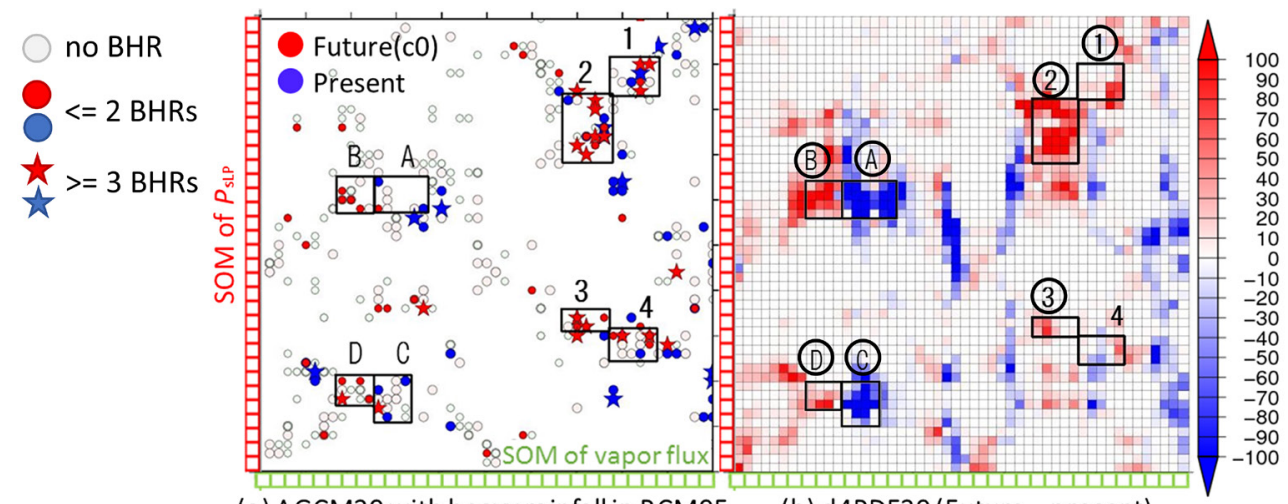

$\begin{array}{ll}\text { (a) AGCM20 with heavy rainfall in RCM05 } & \text { (b) d4PDF20(Future-present) }\end{array}$



(c) The composite of $\boldsymbol{P}_{\text {slp }}$ and $\boldsymbol{F}_{s}$ in pattern 1 4 and A D

Fig. 3. (a) Classification of AGCM $20 P_{\text {slp }}$ and $F_{\mathrm{s}}$ on SOM maps. Red (blue) $\bullet / \star$ mean a future (present) AGCM 20 variables in which at least one/over three BHRs are found in the corresponding NHRCM05 within that 10-days. (b) Classification of d4PDF20 $P_{\mathrm{stp}}$ and $F_{\mathrm{s}}$. The color shows the number difference between the future and present of d4PDF20 ensembles on each node. The nodes inside the circled number of the clusters of $1 \sim 4$ and A D have a $1 \%$ statistically significant difference. (c) The composited $P_{\mathrm{slp}}$ and $F_{\mathrm{s}}$ for each cluster of $1 \sim 4$ and A $\sim \mathrm{D}$. The numbers in parentheses mean the sample number for each cluster. Colors denoted $P_{\text {slp }}$ and arrows for $F_{\text {s }}$ 
high and vapor flux along the periphery of the high. Moreover, most of the nodes composing the patterns 1 3 are in red and 1 3 are circled in Fig. 3b. This means the occurrence frequency of the patterns 1 3 has a statistically significant increase in the future. On the other hand, we can find that patterns A D have the distinctive future change in Figs. $3 \mathrm{~b}$ and $3 \mathrm{c}$. The pattern B (D) has more abundant supply of $F_{\mathrm{s}}$ than the one of A (C) while patterns A-B (C-D) have the same $P_{\text {slp }}$ distribution (each cluster is located at the same horizontal position in SOM). We can see a clear shift to the atmospheric patterns with an abundant vapor flux from the pattern $\mathrm{A}$ to $\mathrm{B}$, and $\mathrm{C}$ to $\mathrm{D}$ in Fig. 3b. However, we cannot find relevant correspondences among the patterns $\mathrm{A} \sim \mathrm{D}$ and BHRs. This study focuses on the future change of heavy rainfall, therefore we only discuss the patterns 1 4, which are highly associated with BHRs, for the linkage between BHRs and atmosphere.

Figure 4 shows (a) the composited equivalent potential temperature at $850 \mathrm{hPa}$ (defined as $\theta_{\mathrm{e}}$ hereafter), and (b) the composited precipitation and the BHRs locations (denoted by $\star)$ when BHRs occurred under the patterns 1 4. These variables are averaged in the present and future, respectively. In the future climate's patterns 1 3, BHRs exist in Japan-sea-side and northern
Japan areas although they do not exist in the present. It is assumed that this future change is due to the northward-invading air mass of high $\theta_{\mathrm{e}}$ in the future. Additionally, BHRs exist around the Pacific side in eastern Japan in all of the future climate's patterns $1 \sim 4$. Kato (2007) pointed out that the Pacific side in eastern Japan does not presently have much heavy rainfall due to no abundant supply of high $\theta_{\mathrm{e}}$ air mass at low level unlike the western Japan. However, these future climate's patterns 1 4 have the inflow of high $\theta_{\mathrm{e}}$ air mass, thus BHRs may occur around the Pacific side in eastern Japan. These results indicate that the northward and eastward-invading air mass of high $\theta_{\mathrm{e}}$ in the future cause the increase of BHR's appearance frequency in areas of Japan-sea-side, northern Japan, and the Pacific side in eastern Japan. Moreover, the increasing trends of the patterns $1 \sim 3$ coincide with the one of BHRs around Japan-sea-side and northern Japan areas shown in Fig. 2.

\subsection{The mechanisms of future change of BHRs in the Pacific side in eastern Japan}

The patterns 1 4 will cause an increase of BHRs in the future around the Pacific side in eastern Japan, i.e., Kanto and Tokai,
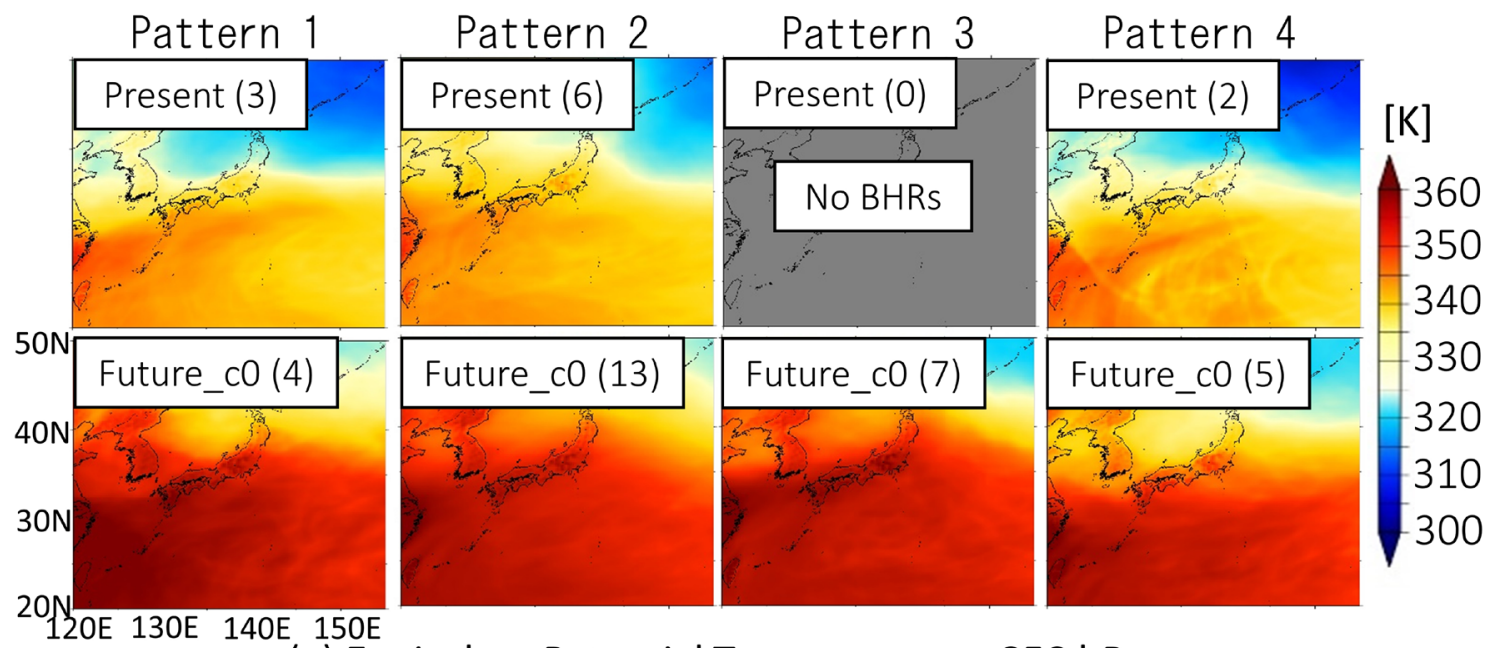

(a) Equivalent Potential Temperature at $850 \mathrm{hPa}$

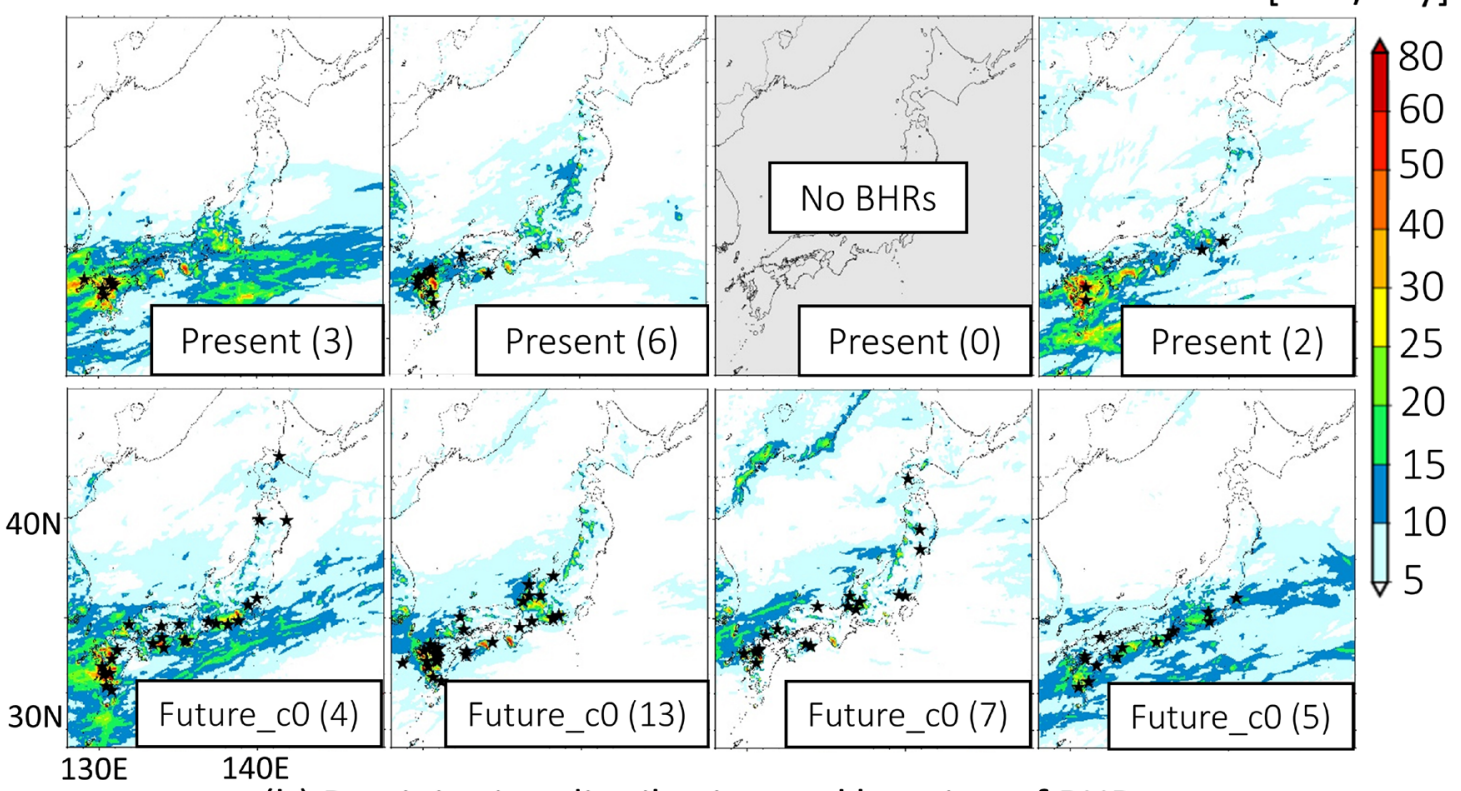

(b) Precipitation distribution and location of BHRs

Fig. 4. (a) The composited $\theta_{\mathrm{e}}$ at $850 \mathrm{hPa}$; and (b) the precipitation distribution and the BHRs locations $(\star)$ when BHRs occurred in the future and present climates. The numbers in parentheses mean the sample number for each cluster. 
where do not have the statistically significant increase of BHRs shown in Fig. 2. Therefore, we further investigated the reason of the future change in this area.

Matsumoto et al. (2013) analyzed the relationship among heavy rainfall and atmospheric patterns in Kanto Region during the Baiu season and pointed out that much heavy rainfall around Kanto is highly related to the cyclones located at south of Japan. We also analyzed the real heavy rainfall in the past for clarifying the BHRs and their typical BHRAP by using radar data and JRA55. Figure 5 shows the radar's precipitation distribution and the 10-days-averaged $P_{\text {sip }}$ and $F_{\mathrm{s}}$ of the past real heavy rainfall in Tokai Region on $11^{\text {th }}$ September 2000 (PS2000) and similar distributions from NHRCM05. Figures $5 \mathrm{a}$ and $5 \mathrm{c}$ have high similarity on the shape and locations of precipitation distribution. Both events were caused by the abundant supply of vapor in the southeast direction (white arrows in Figs. 5b and 5d) pumped up to the north by a cyclone located at south of Japan (black arrows in Figs. $5 \mathrm{~b}$ and $5 \mathrm{~d}$ ), and Pacific high was not westward-protruding. The BHRAPs of other past real heavy rainfall events in the Pacific side area in eastern Japan have the same atmospheric characteristics as PS2000 (see Supplement 2). In short, the typical BHRAP for the Pacific side in eastern Japan in the current climate is related with the cyclones located at south of Japan and southeast $F_{\mathrm{s}}$ inflow to BHRs' locations. Moreover, we confirmed that NHRCM05 can represent such characteristics well.

Next, we checked the future change of the occurrence frequency of this typical BHRAP. Figure 6a shows classification of AGCM20 which BHRs occurred only in the Pacific side in eastern Japan (Kanto and Tokai). Figure $6 \mathrm{~b}$ is same as Fig. 3b. Highlighted in a yellow dashed frame in SOMs in Fig. 6, the nodes show the representative characteristics of this typical BHRAP shown in Fig. 6c. We can find that many present atmospheric patterns with BHRs are classified into the nodes inside that yellow frame in Fig. 6a. Also, there are many nodes inside the yellow frame in Fig.
$6 \mathrm{~b}$ are colored in blue. This means that the occurrence frequency of this typical BHRAP will decrease in the future. On the other hand, many future atmospheres with BHRs are classified into the patterns 1 4. These results indicate that the typical BHRAP for the Pacific side in eastern Japan will change in the future, and the BHRAP for mainly western Japan in the current climate will start to cause heavy rainfall even in eastern Japan in the future (Fig. 7).

\section{Summary}

In this study, the detailed future change of heavy rainfall has been investigated from multiple spatial scales.

We clarified the statistically significant increase in the appearance frequency of BHRs, which are directly obtained from the NHRCM05's precipitation output, in northern Japan and JapanSea-side areas. This future change results from the increase in the BHRAPs with a westward-protruding Pacific high and a northward-invading high $\theta_{\mathrm{e}}$ air mass along the periphery of the high. Moreover, we found that the typical BHRAP will change in the Pacific side in eastern Japan. The occurrence frequency of a typical BHRAP in the current climate, which has a cyclone located at south of Japan, will decrease in the future. Instead, the atmospheric patterns with a westward-protruding Pacific high, which presently cause heavy rainfall mainly in western Japan, will expand the area of heavy rainfall eastward due to eastwardinvading high $\theta_{\mathrm{e}}$ air mass, and the pattern will frequently occur in the future. These significant future changes of atmospheric occurrence frequency are statistically clarified by a huge ensemble of d4PDF20. To our knowledge, this study is the first clarifying the relationship between the future change of Baiu heavy rainfall and atmospheric patterns. In the future, we will further verify our results using other AGCM and AOGCM.

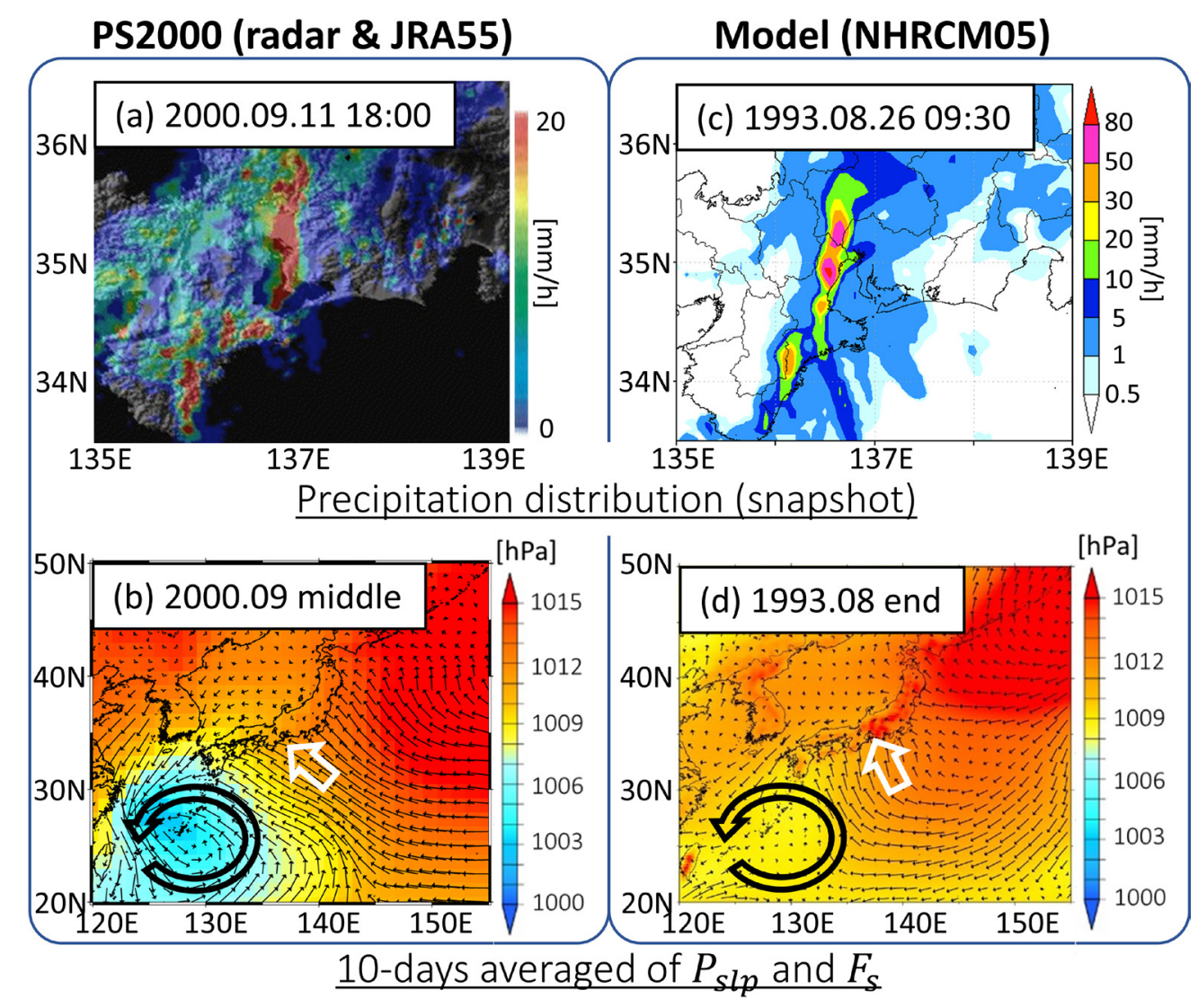

Fig. 5. The precipitation distribution and 10-days-averaged atmospheric circulation patterns of $P_{\text {slp }}$ (color) and $F_{\mathrm{s}}$ (arrow). (a) (b) denote PS2000, (c) (d) for an BHR from NHRCM05 in the Pacific side area in eastern Japan. 

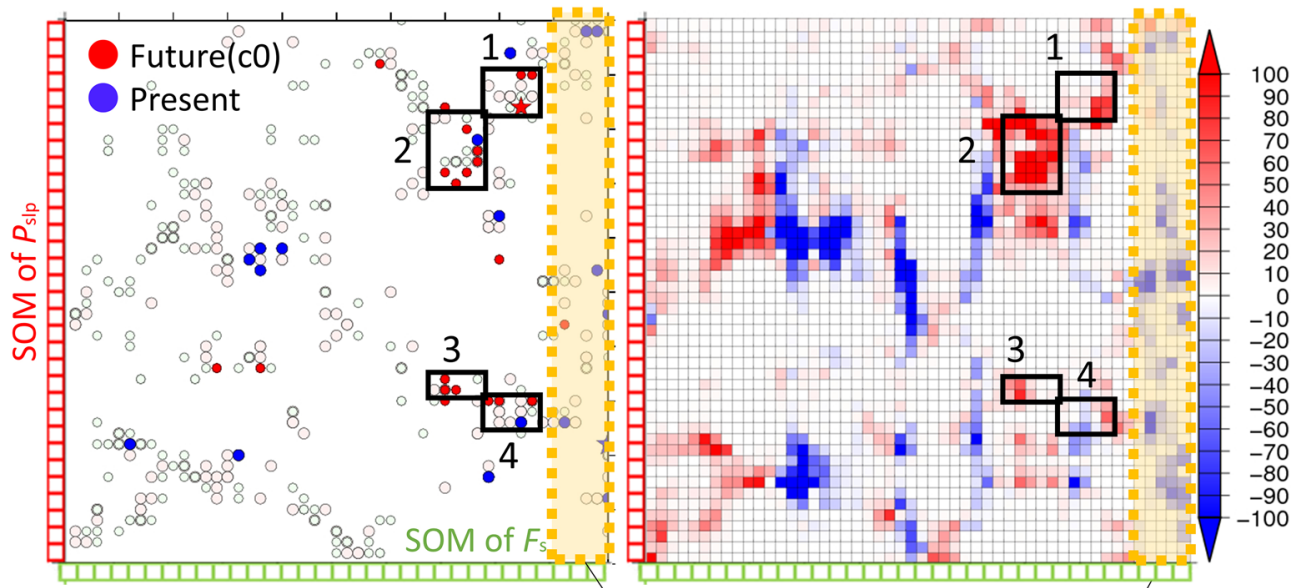

$$
\begin{aligned}
& \text { (a) AGCM20 with BHRs at the Pacific } \\
& \text { side in eastern Japan in NHRCM05 } \\
& \text { no BHR } \\
& <=2 \text { BHRs } \\
& \star>=3 \text { BHRs }
\end{aligned}
$$
side in eastern Japan in NHRCM05

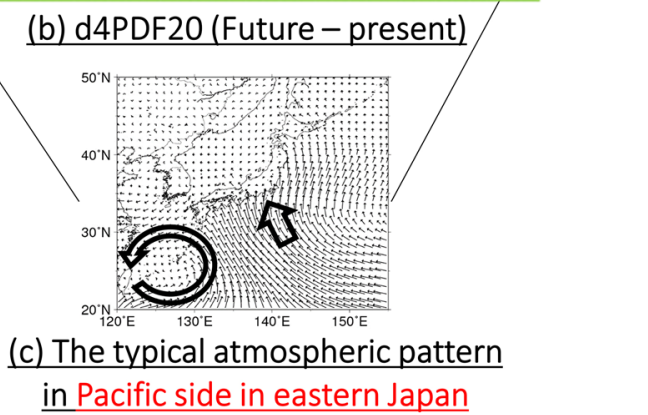

Fig. 6. (a) Same as Fig. 3a except for that 10-days-averaged atmospheric pattern associated with BHRs only in the Pacific side area in eastern Japan. (b) Same as Fig. 3b. (c) The typical atmospheric pattern in the Pacific side in eastern Japan in current climate.
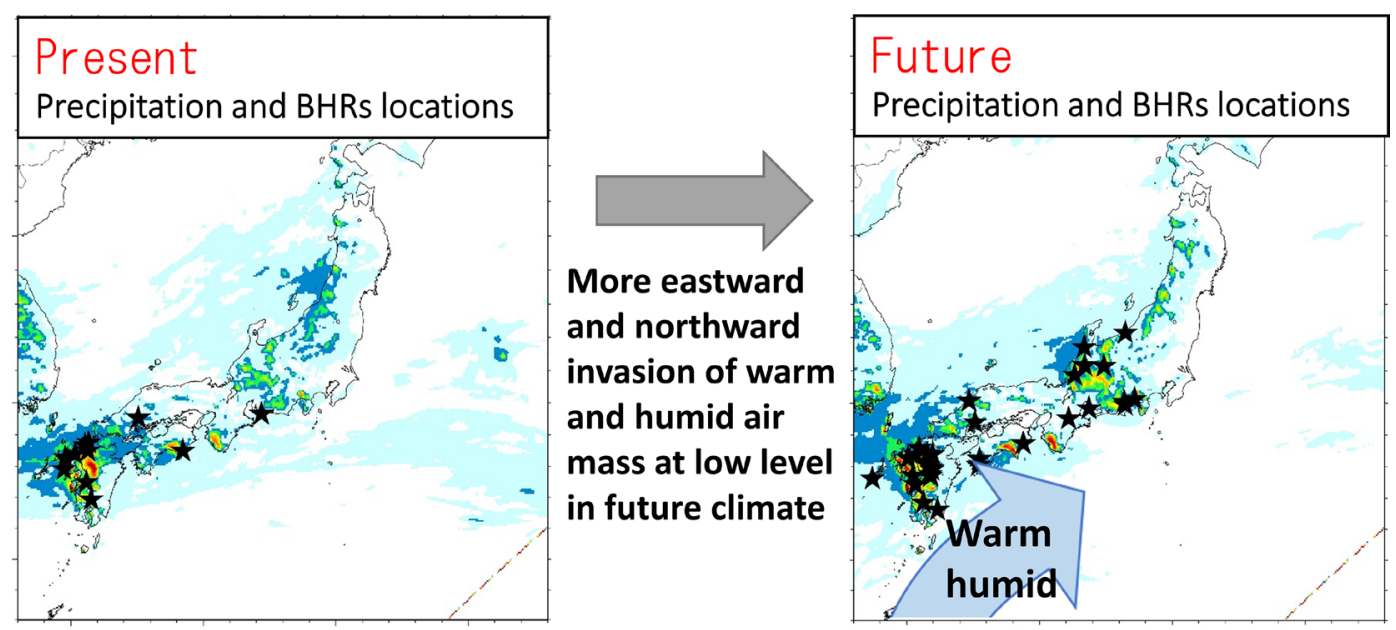

Fig. 7. The schematic figure of the future change of heavy rainfall and atmosphere whose characteristics are westward-protruding Pacific high and vapor flux along the periphery of the Pacific high. These two figures are the composites of precipitation and BHRs locations of atmospheric pattern 2 when BHRs occurred in the future and present climates. Thus, these are the same as these composites of pattern 2 shown in Fig. $4 \mathrm{~b}$.

\section{Acknowledgements}

This study utilized the database for Policy Decision-making for Future climate change (d4PDF) and a non-hydrostatic regional climate model (NHRCM05), which was developed under the "Program for Risk Information on Climate Change (SOUSEI Program)" supported by Ministry of Education, Culture, Sports, Science and Technology, Japan.

\section{Supplement}

Supplement 1 describes the objective criteria for picking up BHRs from the precipitation output of NHRCM05.

Supplement 2 shows the precipitation distribution and 10-daysaveraged atmospheric patterns of $P_{\text {slp }}$ (color) and $F_{\mathrm{s}}$ (arrow). (a) (b) an event in Kanto Region on 27 August 1998, (c) (d) an event in Tokai Region on 28 August 2008. 


\section{References}

Camus, P., A. S. Cofino, F. J. Mendez, and R. Medina, 2011: Multivariate wave climate using self-organizing maps. J. Atmos. Oceanic Technol., 28, 1554-1568.

IPCC, 2000: Special Report on emissions scenarios. A special report of working group III of the Intergovernmental Panel on Climate Change. Cambridge University Press, Cambridge, UK, $570 \mathrm{pp}$.

IPCC, 2013: Climate Change 2013: The Physical Scienve Basis. Contribution of Working Group I to the Fifth Assessment Report of the Intergovernmental Panel on Climate Change. Stocker, T. F., D. Qin, G. K. Plattner, M. Tignor, S. K. Allen, J. Boschung, A. Nauels, Y. Xia, V. Vex, and P. M. Midgley, Eds., Cambridge University Press, Cambridge, UK, and New York, USA, 1535 pp.

Kanada, S., M. Nakano, and T. Kato, 2012: Projections of future changes in precipitation and the vertical structure of the frontal zone during the Baiu season in the vicinity of Japan using a 5-km-mesh regional climate model. J. Meteor. Soc. Japan, 90A, 65-86.

Kato, T., 2007: Baiu frontal zone and heavy rainfall -Conditions for cumulonimbi to develop-. Tenki, 54, 9-12 (in Japanese).

Kitoh, A., T. Ose, K. Kurihara, S. Kusunoki, M. Sugi, and KAKUSHIN Team-3 Modeling Group, 2009: Projection of changes in future weather extremes using super-highresolution global and regional atmospheric models in the KAKUSHIN Program: Results of preliminary experiments. Hydrol. Res. Lett., 3, 49-53.

Kobayashi, S., Y. Ota, Y. Harada, A. Ebita, M. Moriya, H. Onoda, K. Onogi, H. Kamahori, C. Kobayashi, H. Endo, K. Miyaoka, and K. Takahashi, 2015: The JRA-55 reanalysis: General specifications and basic characteristics. J. Meteor. Soc. Japan, 93, 5-48.

Kohonen, T., 1982: Self-Organized formation of topologically correct feature maps. Biol. Cybern., 43, 59-69.

Matsumoto, K., K. Kato, and K. Otani, 2013: Preliminary analyses on the climatological features of precipitation characteristics and large-scale atmospheric fields on the heavy rainfall days in the eastern part of Japan during the mature stage of the Baiu season. Okayama University Earth Science Reports, 20, 25-34 (in Japanese).

Mizuta, R., H. Yoshimura, H. Murakami, M. Matsueda, H. Endo, T. Ose, K. Kamiguchi, M. Hosaka, M. Sugi, S. Yukimoto, S. Kusunoki, and A. Kitoh, 2012: Climate simulations using MRI-AGCM3.2 with $20-\mathrm{km}$ grid. J. Meteor. Soc. Japan, 90A, 253-258.

Mizuta, R., O. Arakawa, T. Ose, S. Kusunoki, H. Endo, and A. Kitoh, 2014: Classification of CMIP5 future climate responses by the tropical sea surface temperature changes. SOLA, 10, 167-171, doi:10.2151/sola.2014-035.
Mizuta, R., A. Murata, M. Ishii, H. Shiogama, K. Hibino, N. Mori, O. Arakawa, Y. Imada, K. Yoshida, T. Aoyagi, H. Kawase, M. Mori, Y. Okada, T. Shimura, T. Nagatomo, M. Ikeda, H. Endo, M. Nosaka, M. Arai, C. Takahashi, K. Tanaka, T. Takemi, Y. Tachikawa, K. Temur, Y. Kamae, M. Watanabe, H. Sasaki, A. Kitoh, I. Takayabu, E. Nakakita, and M. Kimoto, 2016: Over 5000 years of ensemble future climate simulations by $60 \mathrm{~km}$ global and $20 \mathrm{~km}$ regional atmospheric models. Bull. Amer. Meteor. Soc., 98, 1383-1398.

Nakakita, E., T. Miyake, K. Kim, and L. Konoshima, 2012: Fundamental study on future change of localized heavy rainfall during Baiu due to climate change using a regional climate model. J. JSCE, Ser. B1 (Hydraulic Eng.), 68, I_427-I_432 (in Japanese).

Nakakita, E., H. Kusano, Y. Touge, and S. Kim, 2016: Future change in appearance frequency of atmospheric characteristics causing localized heavy rainfall during Baiu season using AGCM Ensembles. Ann. Disast. Prev. Res. Inst., Kyoto University, 59B, 230-248 (in Japanese).

Nakakita, E., and Y. Osakada, 2017: Analyses on the future change of the occurrence frequency of atmosphere causing heavy rainfall in Baiu season by combining SOM Maps. Ann. Disast. Prev. Res. Inst., Kyoto University, 60B, 622-637 (in Japanese).

Nakakita, E., and Y. Osakada, 2018: Estimation of future changes in the heavy rainfall and atmospheric characteristics in Baiu season under climate change. J. JSCE, Ser. B1 (Hydraulic Eng.), 74, I_139-I_144 (in Japanese).

Ninomiya, K., 1984: Characteristics of Baiu front as a predominant subtropical front in the summer Northern Hemisphere. J. Meteor. Soc. Japan, 62, 880-894.

Ohba, M., S. Kadokura, D. Nohara, and Y. Toyoda, 2016: Rainfall downscaling of weekly ensemble forecasts using selforganising maps. Tellus A, 68, 29293, doi:10.3402/tellusa. v68.29293.

Ohba, M., S. Kadokura, Y. Yoshida, D. Nohara, and Y. Toyoda, 2014: Anomalous weather patterns in relation to heavy precipitation events in Japan during the Baiu season. $J$. Hydrometeor., 16, 688-701.

Seko, H., 2010: Study of the shapes and maintenance mechanisms of meso- $\beta$ scale line-shaped precipitation systems in the middle-latitudes. J. Meteor. Soc. Japan, 62, 1-74 (in Japanese).

Ultsch, A., and H. P. Siemon, 1990: Kohonen's self organizing feature maps for exploratory data analysis. Proc. International Neural Network Conference, Kluwer Academic Publisher, Dordrecht, Netherlands, 305-307.

Manuscript received 6 April 2018, accepted 6 June 2018 SOLA: https://www.jstage.jst.go.jp/browse/sola/ 